\title{
Contaminaçáo da pastagem com larvas infectantes de nematoides gastrintestinais após o pastejo de ovelhas resistentes ou susceptíveis à verminose
}

\author{
Pasture contamination with infective larvae of gastrointestinal nematodes after grazing \\ by sheep resistant or susceptible to parasitic infection \\ César Cristiano Bassetto ${ }^{1}$; Bruna Fernanda da Silva ${ }^{1}$; Simone Fernandes ${ }^{2}$; \\ Alessandro Francisco Talamini do Amarante ${ }^{1 *}$ \\ ${ }^{1}$ Departamento de Parasitologia, Instituto de Biociências, Universidade Estadual Paulista - UNESP \\ ${ }^{2}$ Departamento de Produção Animal, Faculdade de Medicina Veterinária e Zootecnia, Universidade Estadual Paulista - UNESP
}

Recebido em 9 de Março de 2009

Aceito em 19 de Maio de 2009

\section{Resumo}

O grau de contaminação da pastagem por larvas de terceiro estágio (L3) de nematoides gastrintestinais foi avaliado em piquetes pastejados por ovelhas resistentes ou susceptíveis à verminose. O experimento foi realizado de 23 de novembro de 2007 a 22 de julho de 2008. Inicialmente, realizou-se a contagem de ovos por grama de fezes (OPG) de amostras individuais de 130 ovelhas adultas da raça Bergamácia. Dessas, foram selecionadas as nove ovelhas com contagens mais elevadas de OPG (susceptíveis) e as $10 \mathrm{com}$ as menores contagens (resistentes). As ovelhas resistentes apresentaram menor contagem de OPG, maiores valores de volume globular, de proteína plasmática total e de eosinófilos sanguíneos, do que as ovelhas susceptíveis. O peso também foi maior no grupo resistente. Na pastagem, foram identificadas larvas de Haemonchus spp., Trichostrongylus spp. e Oesophagostomum spp. Em média, as quantidades de L3 de Haemonchus spp. e de Trichostrongylus spp., na pastagem, foram 2,19 e 2,31 vezes, respectivamente, maiores nos piquetes pastejados pelo grupo susceptível do que nos do grupo resistente. Portanto, os animais susceptíveis devem ser eliminados do rebanho a fim de reduzir a contaminação da pastagem e otimizar a profilaxia das infecçôes por nematoides gastrintestinais.

Palavras-chave: Haemonchus, Trichostrongylus, pastagem, ovinos, profilaxia.

\begin{abstract}
The degree of contamination of herbage with third stage larvae of gastrointestinal nematodes was evaluated in paddocks grazed by resistant or susceptible ewes. The trial occurred from November 23, 2007 to July 22, 2008. Initially, fecal egg counts (FEC) were performed with individual samples of 130 adult ewes of the Bergamacia breed. Of those animals, nine ewes with the highest FEC (susceptible group) and 10 with the lowest counts (resistant group) were selected and moved to separate paddocks. The resistant ewes presented lower FEC, higher values of packed cell volume, total plasma protein and blood eosinophils than the susceptible ewes. The weight was also higher in the resistant group. Haemonchus spp., Trichostrongylus spp. and Oesophagostomum spp. third stage larvae were recovered from pasture. In average, the amount of Haemonchus spp. and Trichostrongylus spp. third stage larvae in the pasture were 2.19 and 2.31 times, respectively, higher in the paddocks grazed by susceptible group in comparison with those grazed by the resistant animals. Therefore, the susceptible animals should be eliminated from the flock in order to reduce pasture contamination and optimize the prophylaxis of gastrointestinal nematode infections.
\end{abstract}

Keywords: Haemonchus, Trichostrongylus, pasture, sheep, prophylaxis.

\footnotetext{
*Autor para correspondência: Alessandro Francisco Talamini do Amarante

Departamento de Parasitologia, Instituto de Biociências,

Universidade Estadual Paulista - UNESP, CP 510, CEP 18.618-000,

Botucatu - SP, Brasil;

e-mail: amarante@ibb.unesp.br
} 


\section{Introdução}

A verminose é o principal problema sanitário da criação de ovinos, na qual causa sérios prejuízos devido à redução da produtividade do rebanho e mortalidade de animais. Existem várias espécies de helmintos gastrintestinais, porém, em regiôes com clima tropical e subtropical, duas espécies são predominantes: Haemonchus contortus e Trichostrongylus colubriformis, sendo a primeira a principal espécie parasita de pequenos ruminantes (AMARANTE et al., 2004; ROCHA et al., 2008).

Os animais infectam-se ao ingerirem as larvas infectantes (L3) presentes na pastagem. Os próprios animais são as fontes de contaminação do ambiente, pois eliminam nas fezes os ovos dos nematoides, os quais irão se desenvolver até darem origem às L3 (OLIVEIRA-SEQUEIRA; AMARANTE, 2001). Barger (1989) descreveu que a seleção de ovinos resistentes, resulta em redução de 80 a 90\% da carga parasitária, em comparação com rebanhos que não foram submetidos à seleção. Além disso, a seleção de animais resistentes pode reduzir significativamente os picos sazonais na carga parasitária, bem como o número de larvas na pastagem. Portanto, o ideal seria evitar, ou pelo menos reduzir, a contaminação da pastagem a partir dos animais nela colocados. Nesse caso, animais mais resistentes ao parasitismo eliminariam menor quantidade de ovos nas fezes, o que, em teoria, propiciaria redução na contaminação das pastagens pelas L3. Estudos realizados na Nova Zelândia comprovaram que a quantidade de L3 na planta forrageira, pastejada por ovinos resistentes, foi $50 \%$ menor do que a que foi pastejada por ovinos susceptíveis (BISSET et al., 1997). Além disso, um animal com carga parasitária elevada de uma determinada espécie de nematoide apresenta tendência de também albergar maior número das demais espécies de nematoides (STEAR et al., 1998; AMARANTE et al., 2004).

Este estudo foi motivado pela falta de informaçóes sobre a contaminação das pastagens utilizadas por ovinos resistentes e susceptíveis às infecçóes por nematoides gastrintestinais, nas condiçôes brasileiras. Avaliou-se também o desempenho dos animais resistentes e susceptíveis.

\section{Material e Métodos}

\section{Descrição do experimento}

O experimento foi conduzido no setor de ovinos, localizado na Fazenda Edgardia, da Faculdade de Medicina Veterinária e Zootecnia (FMVZ), Universidade Estadual Paulista (UNESP) - Campus de Botucatu - SP. Sua posição geográfica está definida pelas coordenadas geográficas $48^{\circ} 26^{\prime} \mathrm{O}$ e $22^{\circ} 51^{\prime} \mathrm{S}$.

As coletas foram realizadas de 23 de novembro de 2007 a 22 de julho de 2008, sendo as três primeiras realizadas a cada 24 dias, a fim de selecionar os animais resistentes e susceptíveis com base em contagens de ovos por grama de fezes (OPG). As coletas seguintes foram realizadas a cada 14 dias, com início no dia 22 de janeiro de 2008. A partir dessa data, também foram coletadas amostras de sangue para determinar o volume globular (VG), proteína plasmática total (PPT) e contagem de eosinófilos do sangue. No mesmo dia, realizou-se a pesagem dos animais.

Nas três primeiras coletas, realizadas nos dias 23 de novembro, 17 de dezembro de 2007 e 10 de janeiro de 2008, foram avaliadas 130 ovelhas, sendo coletadas apenas fezes para realização de exames coprológicos (OPG e coprocultura). Os resultados das contagens de OPG foram utilizados para calcular a média individual de OPG, o que permitiu selecionar as 20 ovelhas com as médias mais baixas de OPG (grupo resistente) e as $20 \mathrm{com}$ as médias mais elevadas (grupo susceptível). Os resultados dessas três primeiras coletas foram utilizados apenas para identificar os dois grupos de animais e, portanto, não foram apresentados nos resultados finais.

Os dois grupos foram submetidos a condições similares de manejo em piquetes adjacentes com pastagem formada por Panicum maximum, variedade Tanzânia. Foram utilizados quatro piquetes por grupo, numerados de 1 a 8 , um ao lado do outro, com 0,3 hectare de área cada um. As ovelhas permaneceram em cada piquete por um período de 10 dias, o grupo resistente foi alocado nos piquetes de números ímpares, e o grupo susceptível, nos piquetes de números pares.

$\mathrm{Na}$ coleta realizada no dia 22 de janeiro, observaram-se, em quase todas as ovelhas, sinais clínicos de oestrose. Por isso foi administrado em todos os animais do rebanho ivermectina (0,2 mg. $\mathrm{kg}^{-1}$; Ivomec ${ }^{\circledR}$ Injetável - Merial), para eliminar as larvas de Oestrus ovis.

Nos resultados das coletas realizadas nos dias 22 de janeiro, 7 e 21 de fevereiro, observou-se que, no grupo resistente, havia várias ovelhas com contagem alta de OPG e, no grupo susceptível, várias ovelhas com contagem baixa. Esses animais foram excluídos do experimento, o que resultou em 12 ovelhas em cada grupo. Por essa razão, reduziu-se também a partir da quarta coleta (5 de março), o número de piquetes, que passou de oito para seis, ou seja, três piquetes por grupo.

Durante a quarta coleta, foi constatada a gestação indesejada de duas ovelhas do grupo susceptível. Como no periparto aumenta a susceptibilidade das ovelhas à verminose (AMARANTE et al., 1992), optou-se por excluí-las do estudo. Por essa razão, duas ovelhas do grupo resistente também foram retiradas do experimento, no qual foram escolhidas as duas ovelhas que apresentavam as contagens mais elevadas de OPG.

Na sétima coleta, uma ovelha do grupo susceptível foi tratada com levamisol (9,4 mg. $\mathrm{kg}^{-1}$, Ripercol ${ }^{\circledR}$ L 150 F, Fort Dodge) e confinada, pois a mesma já havia recebido levamisol $\left(4,7 \mathrm{mg} \cdot \mathrm{kg}^{-1}\right.$, Ripercol ${ }^{\circledR}$ L 150 F, Fort Dodge), durante a coleta anterior, e a contagem de OPG se manteve elevada, tendo quase triplicado depois do tratamento. Pelo fato dessa ovelha ter recebido tratamento com anti-helmíntico por cinco vezes consecutivas e ficado em sistema de confinamento da sexta coleta (1 de abril) até a décima coleta (27 de maio), ela foi retirada do experimento, e os seus resultados não foram utilizados. Portanto, o grupo resistente foi constituído de 10 animais e o grupo susceptível de nove animais.

No período correspondente à sexta e à oitava coleta (1 a 29 de abril), as ovelhas foram acometidas por ectima contagioso. 


\section{Exames coproparasitológicos}

Em cada uma das amostras de fezes, coletadas diretamente do reto do animal, realizou-se a contagem de OPG, de acordo com a técnica de Gordon e Whitlock (1939). As coproculturas (ROBERTS; O'SULLIVAN, 1950) foram realizadas, separadamente, sendo uma para cada grupo. As larvas infectantes obtidas foram identificadas de acordo com Keith (1953).

\section{Exames hematológicos}

Amostras de sangue foram coletadas da veia jugular, em tubos de vacutainer, contendo EDTA (ácido etilenodiaminotetracético potássio). O VG foi determinado por centrifugação do sangue em tubos de micro-hematócrito. Os níveis de PPT foram estimados, utilizando-se refratômetro ocular (Modelo SPR-N, marca Atago). Os eosinófilos do sangue foram quantificados, em câmara de Neubauer, após terem sido corados com soluçâo de Carpentier (DAWKINS et al., 1989). As contagens foram expressas em número de eosinófilos por microlitro de sangue.

\section{Pesagem das ovelhas}

As ovelhas foram pesadas por ocasião das coletas em uma balança digital.

\section{Quantificação e identificação de larvas infectantes na pastagem}

No dia da coleta das amostras fecais e sanguíneas, também foram coletadas amostras da pastagem para estimar a concentraçáo média de larvas infectantes de nematoides gastrintestinais por quilograma de matéria seca ( $\left.\mathrm{L} 3 \cdot \mathrm{kg}^{-1} \mathrm{MS}\right)$.

As amostras foram coletadas individualmente de todos os piquetes, a partir das 10 horas da manhã, seguindo um traçado em forma de "W" previamente determinado no local (TAYLOR, 1939). O coletor seguiu esse traçado coletando manualmente uma amostra de capim a cada quatro passos, aproximadamente a cada $3,5 \mathrm{~m}$ de distância. O capim foi cortado rente ao solo com uma tesoura e colocados em sacos plásticos previamente identificados até serem processadas no laboratório.

No laboratório, as amostras de capim foram colocadas separadamente em baldes, onde permaneceram imersas em quatro litros d'água por quatro horas. Após esse período, cada amostra foi transferida para outro balde já contendo quatro litros d'água, permanecendo imerso por mais três horas, totalizando, assim, sete horas de imersão da amostra de capim em água (NIEZEN et al., 1998). Além disso, foram adicionados $0,5 \mathrm{~mL}$ de detergente neutro em cada balde para diminuir a tensão superficial da água, propiciando, mais facilmente, a separação das larvas do capim.

Decorridas as sete horas, as amostras de capim foram retiradas dos baldes, embaladas em sacos de papel e secas em estufa a $60^{\circ} \mathrm{C}$, por 72 horas, para determinar a matéria seca.
A água dos baldes permaneceu em repouso por 24 horas e, então, o sobrenadante foi retirado, e o sedimento transferido para um cálice de sedimentação. Para que as larvas fossem separadas do sedimento, o procedimento de sua recuperação e quantificaçáo foi descrito por Carneiro e Amarante (2008).

Todas as larvas recuperadas das amostras de capim foram mortas e coradas com lugol, identificadas de acordo com Keith (1953) e quantificadas.

\section{Análise estatística}

Os dados foram submetidos à análise de variância (Oneway analysis of variance) com a utilização do programa Minitab (Versão 11). As médias foram comparadas pelo Teste de Tukey com nível de significância de 5\%. Os dados referentes às contagens de OPG e eosinófilos foram analisados sob transformação logarítmica $(\log (x+1))$. No entanto, para facilitar a compreensão, nos resultados estão apresentadas as médias aritméticas ( \pm erro padrão).

Os dados referentes à quantificação de larvas na pastagem foram analisados com o procedimento GLM do programa Minitab (Versão 11), com dois grupos (resistente e susceptível) e 14 coletas, no modelo estatístico.

\section{Resultados}

\section{Exames coproparasitológicos}

O valor médio da contagem de OPG do grupo susceptível foi maior do que o do grupo resistente em todas as coletas, com diferença significativa entre elas, nos dias 22 de janeiro, 21 de fevereiro, 5 de março, 29 de abril, 13 e 27 de maio e 10 de junho (Figura 1). O grupo resistente apresentou média geral de 885 OPG e o grupo susceptível média geral de 3.640 OPG. O valor médio na contagem de OPG do grupo susceptível foi, portanto, 4,1 vezes maior que o valor da contagem de OPG do grupo resistente.

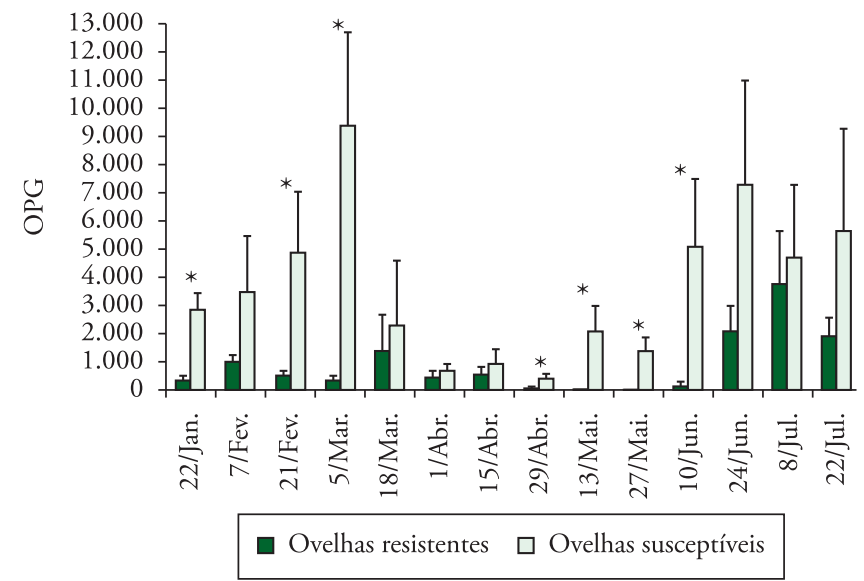

Figura 1. Número médio de ovos por grama de fezes (OPG) de ovelhas resistentes e de ovelhas susceptíveis às infecçôes naturais por nematoides. Barra indica erro padrão, $\mathrm{e}^{*}$ indica diferença estatística entre as médias $(\mathrm{P}<0,05)$. 
As coproculturas do grupo resistente apresentaram, em média, 98\% Haemonchus spp., 0,4\% Trichostrongylus spp. e 1,6\% Oesophagostomum spp.; e o grupo susceptível, 84,5\% Haemonchus spp., 15,1\% Trichostrongylus spp. e 0,5\% Oesophagostomum spp.

\section{Exames hematológicos}

O VG do grupo resistente foi igual ou inferior ao do grupo susceptível, no período em que as ovelhas foram acometidas por ectima contagioso, de 1 a 29 de abril. Nas demais coletas, o VG do grupo resistente foi mais elevado com diferença significativa em três coletas: 22 de janeiro, 5 e 18 de março (Figura 2a).

As médias de PPT foram maiores no grupo resistente em doze coletas. Na oitava coleta (29 de abril), a média da PPT dos dois grupos foi igual, e na nona coleta (13 de maio), a PPT foi maior no grupo susceptível, resultado que se repetiu no período em que as ovelhas apresentaram ectima contagioso. Houve diferença significativa em quatro coletas, realizadas nos dias 5 e 18 de março, 10 e 24 de junho (Figura $2 b$ ).

O número médio de eosinófilos foi maior no grupo resistente em todas as ocasióes, com exceção dos dias 21 de fevereiro e 5 de março. Não houve diferença significativa entre os grupos durante todo o experimento (Figura 2c).

\section{Pesagem}

O peso das ovelhas resistentes foi sempre maior do que o das ovelhas susceptíveis, com diferença significativa entre as médias em três coletas: 5 de março, 27 de maio e 8 de julho (Figura 3).

\section{Quantificação e identificação de larvas infectantes na pastagem}

Em média, a quantidade de L3 de Haemonchus spp. foi 2,19 vezes maior na pastagem utilizada pelas ovelhas susceptíveis do que na pastagem das ovelhas resistentes. As médias gerais de L3. $\mathrm{kg}^{-1} \mathrm{MS}$ foram de 18,6 L3. $\mathrm{kg}^{-1} \mathrm{MS}$, nos piquetes do grupo resistente, e de 40,6 L3. $\mathrm{kg}^{-1} \mathrm{MS}$, nos piquetes do grupo susceptível, não havendo diferença estatística significativa $(\mathrm{P}>0,05)$.

Em apenas quatro coletas (22 de janeiro, 5 de março, 27 de maio e 24 de junho), o número de L3 de Haemonchus spp., na pastagem do grupo resistente, foi maior que a quantidade de L3 na pastagem do grupo susceptível.

Em relaçáo à contaminaçáo da pastagem por L3 de Trichostrongylus spp., a quantidade foi 2,31 vezes maior na pastagem utilizada pelas ovelhas susceptíveis do que na pastagem das ovelhas resistentes. A média geral dos piquetes pastejados pelos animais susceptíveis (7,2 L3. $\left.\mathrm{kg}^{-1} \mathrm{MS}\right)$ foi significativamente mais
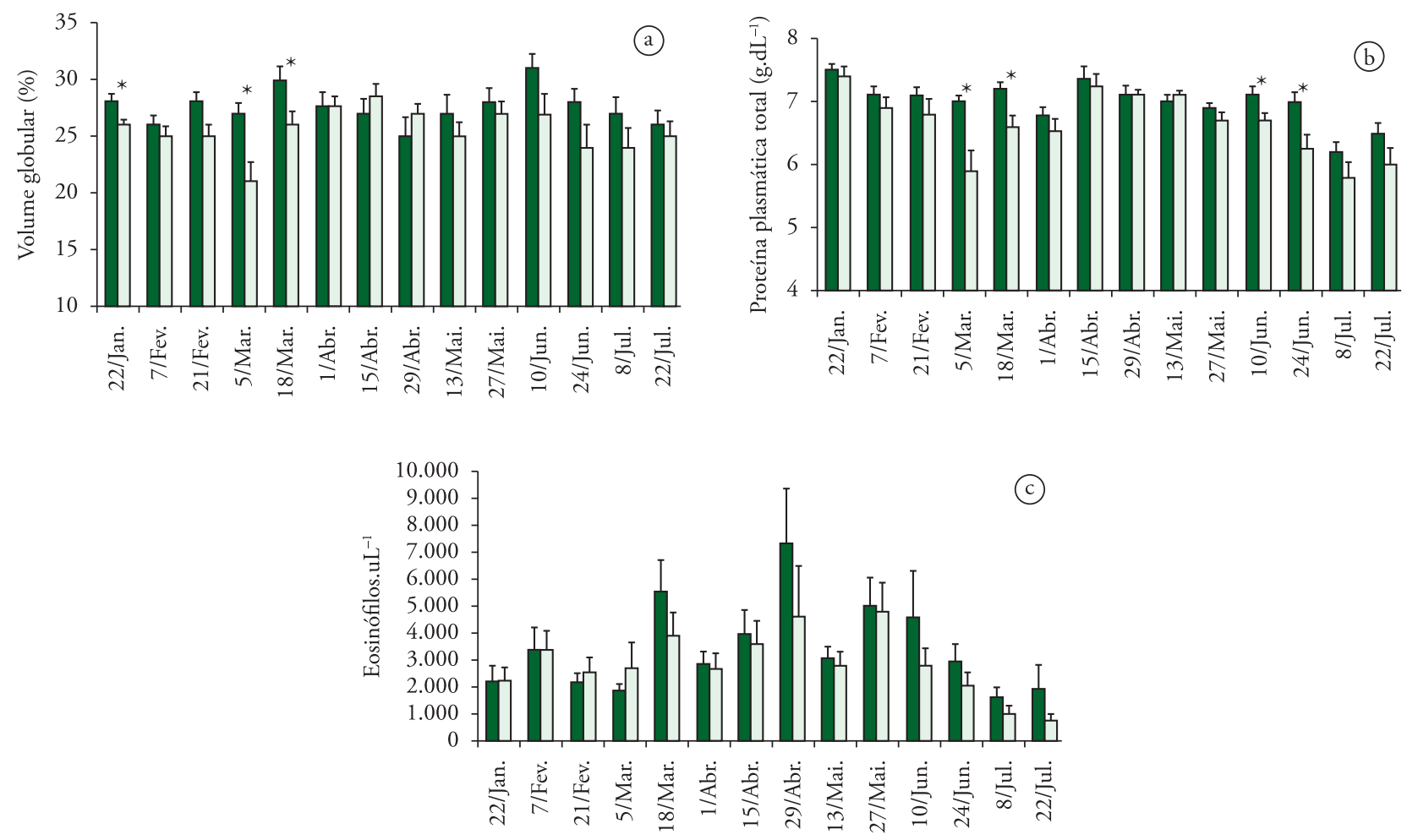

$\square$ Ovelhas resistentes $\square$ Ovelhas susceptíveis

Figura 2. a) Valores médios do volume globular (\%); b) proteína plasmática total e c) eosinófilos sanguíneos (células. $\mu \mathrm{L}^{-1}$ ) de ovelhas resistentes e de ovelhas susceptíveis às infecçóes naturais por nematoides gastrintestinais. Barra indica erro padrão e * indica diferença estatística entre as médias $(\mathrm{P}<0,05)$. 


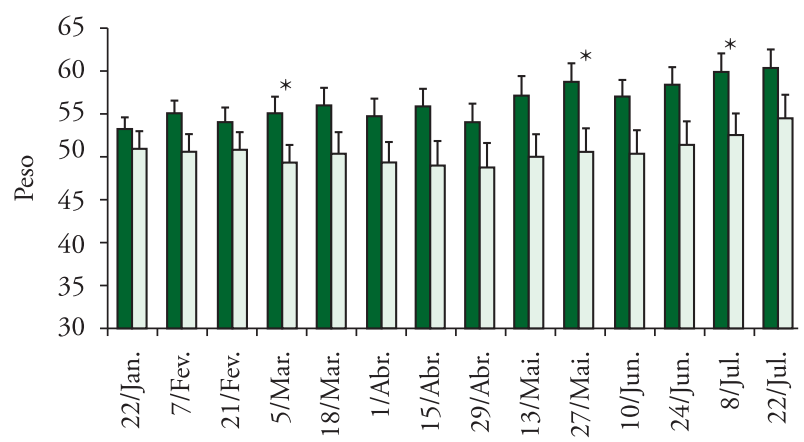

$\square$ Ovelhas resistentes $\square$ Ovelhas susceptíveis

Figura 3. Peso médio de ovelhas resistentes e de ovelhas susceptíveis às infecçóes naturais por nematoides gastrintestinais. Barra indica erro padrão $\mathrm{e}^{*}$ indica diferença estatística entre as médias $(\mathrm{P}<0,05)$.

Tabela 1. Média de larvas infectantes por kg de matéria seca, em piquetes pastejados por ovelhas resistentes ou ovelhas susceptíveis às infecçóes naturais por nematoides gastrintestinais.

\begin{tabular}{cccccc}
\hline Coleta & \multicolumn{2}{c}{ Haemonchus spp. } & & \multicolumn{2}{c}{ Trichostrongylus spp. } \\
\cline { 1 - 3 } \cline { 5 - 6 } & $\begin{array}{c}\text { Grupo } \\
\text { resistente }\end{array}$ & $\begin{array}{c}\text { Grupo } \\
\text { susceptível }\end{array}$ & & $\begin{array}{c}\text { Grupo } \\
\text { resistente }\end{array}$ & $\begin{array}{c}\text { Grupo } \\
\text { susceptível }\end{array}$ \\
\hline 22/jan & 19,7 & 14,5 & & 0,0 & 1,5 \\
7/fev & 78,0 & 114,0 & & 27,0 & 14,3 \\
21/fev & 35,8 & 80,5 & & 0,0 & 3,3 \\
5/mar & 3,0 & 50,3 & & 0,0 & 0,0 \\
18/mar & 14,3 & 12,7 & & 4,0 & 16,7 \\
1/abr & 27,3 & 76,0 & & 0,0 & 4,0 \\
15/abr & 30,3 & 61,0 & & 6,0 & 23,7 \\
29/abr & 7,3 & 38,3 & & 0,0 & 2,3 \\
13/abr & 8,0 & 71,7 & & 0,0 & 10,0 \\
27/mai & 13,3 & 4,0 & & 0,0 & 8,0 \\
10/jun & 0,0 & 0,0 & & 0,0 & 6,0 \\
24/jun & 21,0 & 3,3 & & 6,7 & 9,3 \\
8/jul & 2,0 & 14,3 & & 0,0 & 1,7 \\
22/jul & 0,0 & 28,0 & & 0,0 & 0,0 \\
Média geral & $18,6 \mathrm{a}$ & $40,6 \mathrm{a}$ & & $3,1 \mathrm{a}$ & $7,2 \mathrm{~b}$ \\
\hline
\end{tabular}

Para cada gênero, médias gerais seguidas de letras iguais não são diferentes estatisticamente $(\mathrm{P}>0,05)$.

elevada do que a contaminação da pastagem onde foram alocados os animais resistentes $\left(3,1 \mathrm{~L} 3 \cdot \mathrm{kg}^{-1} \mathrm{MS}\right)(\mathrm{P}<0,05)$.

Foram identificadas larvas infectantes de Trichostrongylus spp., no grupo resistente, em apenas quatro coletas (7 de fevereiro, $18 \mathrm{de}$ março, 15 de abril e 24 de junho). Por outro lado, nos piquetes do grupo susceptível, em apenas duas coletas, não foram identificadas larvas infectantes de Trichostrongylus spp. (5 de março e 22 de julho). Apenas no dia 7 de fevereiro, a contagem de L3 foi mais elevada no grupo resistente do que no grupo susceptível (Tabela 1).

Foram encontradas L3 de Oesophagostomum spp. nos piquetes dos dois grupos, porém em pequena quantidade.

\section{Discussão}

De acordo com os resultados do presente experimento, pôde-se observar que as contagens seriadas de OPG permitiram selecionar animais resistentes aos nematoides gastrintestinais. Porém, a identificação só foi precisa após seis avaliaçóes. A contagem de OPG também se mostrou como uma ferramenta eficiente para a seleção de animais resistentes em pesquisas realizadas em outros países (ALBERS et al., 1987; BISHOP; STEAR, 1999; MILLER et al., 2006). Apesar das variaçóes nas médias de OPG, observou-se contagem 4,1 vezes maior no grupo dos animais susceptíveis comparado aos resistentes. Resultados similares foram observados em estudo realizado na Escócia por Bishop e Stear (1997).

As ovelhas resistentes apresentaram maiores valores de VG e PPT que as ovelhas susceptíveis. Animais com carga parasitária elevada apresentam valores reduzidos de VG e PPT devido a espoliação produzida pelos parasitos (AMARANTE et al., 2004; BRICARELLO et al., 2004). Portanto, as diferenças observadas entre os grupos decorreram dos efeitos deletérios do parasitismo. Os nematoides parasitas do intestino, como é o caso de T. colubriformis, podem provocar redução no apetite, distúrbios na digestão e na absorção dos nutrientes, com consequente redução na conversão alimentar (CARDIA, 2009). Já H. contortus é um parasita hematófago. Em decorrência do parasitismo simultâneo pelas duas espécies de nematoides, os animais podem apresentar perda de peso, anemia e hipoproteinemia, com consequente redução na produtividade.

Embora sem diferença estatística significativa, as ovelhas do grupo resistente apresentaram maior média de eosinófilos do que as ovelhas do grupo susceptível, o que indica a participação dessas células na defesa dos animais contra os parasitas. Esses achados concordam com as observaçóes de Amarante et al. (2007), que verificaram relação inversa entre o número de células inflamatórias no intestino delgado (mastócitos, eosinófilos e leucócitos globulares) e os valores de OPG. Da mesma forma, Dawkins et al. (1989) e Stear et al. (2002) relataram que o número de eosinófilos no sangue foi maior em cordeiros com menor OPG.

Observou-se que as ovelhas resistentes apresentaram peso superior com diferença média de $6 \mathrm{~kg}$ entre os dois grupos ao final do experimento. Da mesma forma, Bisset et al. (1997) observaram que cordeiros Romney resistentes foram mais pesados que os susceptíveis; e Bricarello et al. (2004) observaram que o ganho de peso de cordeiros resistentes da raça Crioula Lanada foi maior do que o de cordeiros susceptíveis da raça Corriedale.

A contaminaçáo da pastagem do grupo susceptível superou em mais de duas vezes a contaminação da pastagem do grupo resistente. Bisset et al. (1997) e Barger (1989) também observaram que a população de larvas na pastagem dos ovinos resistentes foi menor do que na dos ovinos susceptíveis.

Bishop e Stear (1999) relataram que o aumento da contaminaçáo da pastagem é acompanhado por redução na produtividade. Resultados similares foram registrados no presente estudo, no qual as ovelhas resistentes, ao eliminar número menor de ovos nas fezes, contaminaram menos a pastagem e, em consequência apresentaram maior produtividade. 
Em conclusão, os animais susceptíveis às infecçôes por nematoides gastrintestinais, uma vez identificados, devem ser eliminados do rebanho, pois são grandes contaminadores da pastagem. Em consequência da maior exposição aos parasitas, apresentam redução na produtividade.

\section{Agradecimentos}

Agradecemos a Raquel A. da Rocha, pelo auxílio na fase inicial do experimento.

\section{Referências}

ALBERS, G. A. A. et al. The genetics of resistance and resilience to Haemonchus contortus infection in young Merino sheep. International Journal for Parasitology, v. 17, p. 1355-1363, 1987.

AMARANTE, A. F. T. et al. Eliminação de ovos de nematódeos gastrintestinais por ovelhas de quatro raças durante diferentes fases reprodutivas. Pesquisa Agropecuária Brasileira, v. 27, n. 1, p. 47-51, 1992.

AMARANTE, A. F. T. et al. Resistance of Santa Ines, Suffolk and Ile de France sheep to naturally acquired gastrointestinal nematode infections. Veterinary Parasitology, v. 120, n. 1-2, p. 91-106, 2004.

AMARANTE, A. F. T. et al. Relationship of intestinal histology with the resistance to Trichostrongylus colubriformis infection in three breeds of sheep. Pesquisa Veterinária Brasileira, v. 27, n. 1, p. 43-48, 2007.

BARGER, I. A. Genetic resistance of hosts and its influence on epidemiology. Veterinary Parasitology, v. 32, p. 21-35, 1989.

BISHOP, S. C.; STEAR, M. J. Modelling responses to selection for resistance to gastro-intestinal parasites in sheep. Animal Science, v. 64, n. 3, p. 469-478, 1997.

BISHOP, S. C.; STEAR, M. J. Genetic and epidemiological relationships between productivity and disease resistance: gastro-intestinal parasite infection in growing lambs. Animal Science, v. 69, n. 3, p. 515-524, 1999.

BISSET, S. A. et al. Epidemiology of nematodosis in Romney lambs selectively bred for resistance or susceptibility to nematode infection. Veterinary Parasitology, v. 70, n. 4, p. 255-269, 1997.

BRICARELLO, P. A. et al. Worm burden and immunological responses in Corriedale and Crioula Lanada sheep following natural infection with Haemonchus contortus. Small Ruminant Research, v. 51, n. 1, p. 75-83, 2004.

CARDIA, D. F. F. Resposta imunológica e fisiopatologia das infecçóes artificiais por Trichostrongylus colubriformis em cordeiros Santa Inês.
Botucatu, 2009. 42 f. Dissertação (Mestrado) - Faculdade de Medicina Veterinária e Zootecnia, Universidade Estadual Paulista.

CARNEIRO, R. D.; AMARANTE, A. F. T. Seasonal effect of three pasture plants species on the free-living stages of Haemonchus contortus. Arquivo Brasileiro de Medicina Veterinária e Zootecnia, v. 60, n. 4, p. 864-872, 2008.

DAWKINS, H. J. S.; WINDON, R. G.; EAGLESON, G. K. Eosinophil responses in sheep select for high and low responsiveness to Trichostrongylus colubriformis. International Journal for Parasitology, v. 19, n. 2, p. 199-205, 1989.

GORDON, H. M.; WHITLOCK, H. V. A new technique for counting nematode eggs in sheep faeces. Journal of the Council for Scientific Industrial Research, v. 12, p. 50-52, 1939.

KEITH, R. K. The differentiation of the infective larvae of some common nematode parasites of cattle. Australian Journal of Zoology, v. 1, n. 2, p. 223-235, 1953.

MILLER, J. E. et al. Segregation of natural and experimental gastrointestinal nematode infection in $\mathrm{F}_{2}$ progeny of susceptible Suffolk and resistant Gulf Coast Native sheep and its usefulness in assessment of genetic variation. Veterinary Parasitology, v. 140, n. 1-2, p. 83-89, 2006.

NiEZEN, J. H.; WAGHORN, G. C.; CHARlESTON, W. A. G. Establishment and fecundity of Ostertagia circumcincta and Trichostrongylus colubriformis in lambs fed lotus (Lotus pedunculatus) or perennial ryegrass (Lolium perenne). Veterinary Parasitology, v. 78, n. 1, p. 13-21, 1998.

OLIVEIRA-SEQUEIRA, T. C. G.; AMARANTE, A. F. T. Parasitologia Animal: Animais de Produção. Rio de Janeiro: EPUB, 2001. 148 p.

ROBERTS, F. H. S.; O’SULLIVAN, S. P. Methods for egg counts and larval cultures for strongyles infesting the gastro-intestinal tract of cattle. Australian Journal of Agriculture Research, v. 1, n. 1, p. 99-102, 1950

ROCHA, R. A. et al. Sheep and cattle grazing alternately: Nematode parasitism and pasture decontamination. Small Ruminant Research, v. 75, n. 2-3, p. 135-143, 2008.

STEAR, M. J. et al. The processes influencing the distribution of parasitic nematodes among naturally infected lambs. Parasitology, v. 117, n. 2, p. $165-171,1998$.

STEAR, M. J. et al. Eosinophilia as a marker of resistance to Teladorsagia circumcincta in Scottish Blackface lambs. Parasitology, v. 124, n. 5, p. 553-560, 2002.

TAYLOR, E. L. Technique for the estimation of pasture infestation by strongyloid larvae. Parasitology, v. 31, n. 4, p. 473-478, 1939. 